\title{
Design of metal plate temperature sensor based on fiber bragg grating (FBG)
}

\author{
Nani Fadzlina Naim, Nur Shahira Anuar, Suzi Seroja Sarnin, Norsuzila Yaa'cob \\ Fakulti Kejuruteraan Elektrik, Universiti Teknologi MARA (UiTM), Malaysia
}

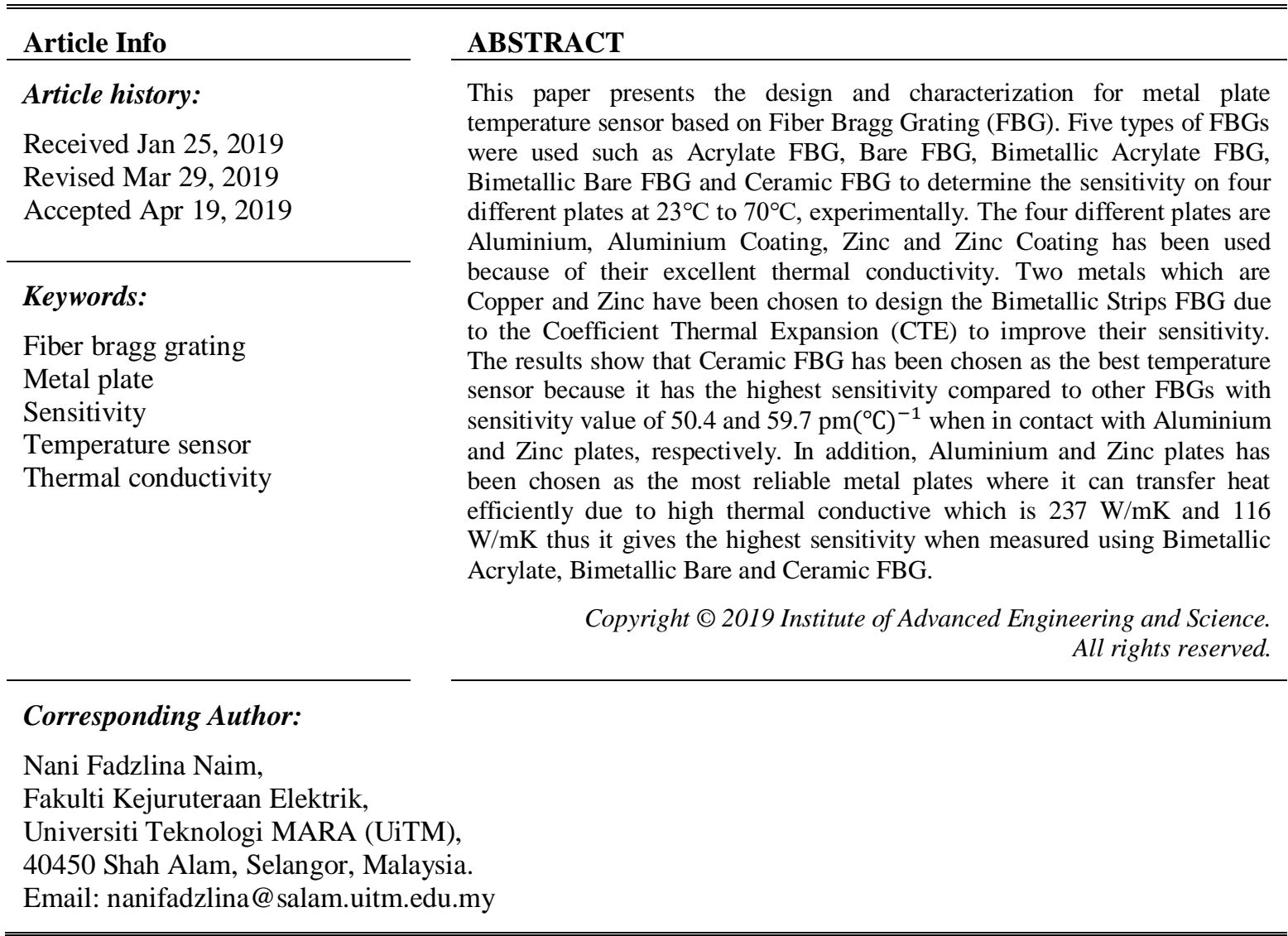

\section{INTRODUCTION}

Fiber Bragg Grating (FBG) is a unique fiber-optical passive tool that grows most rapidly. Due to the presence of FBG in fiber field and countless other related fields, there will be a new practical revolution [1]. Simple manufacture, low attenuation, temperature measurements, strains and strong reflected signal are the main characteristics of FBG [2]. FBG are formed by a periodic modulation of the refraction index fiber core along the longitudinal direction. Due to Fresnel reflection, light that travels along the fiber core will be weakly reflected by each grating plane. All the reflected light will combine in backward direction [3]. Meanwhile, the characteristics of FBG temperature sensor are thin, strong, heat resistance, low attenuation signals, light and transmitting together [4-5]. The working principle of FBG is shown in Figure 1. The broad spectrum of light is transmitted to the FBG and the FBG segments will reflect constructive interference at Bragg wavelength [6]. It also can be recognized as a potential application in space vehicle for the fuel level measurement and to monitor the operational strength of the vehicle. Space vehicle functions are measuring the fuel level that is kept at a very low temperature and the sensitivity temperature of FBG is around $13 \mathrm{pm} /{ }^{\circ} \mathrm{C}$ at the wavelength of $1550 \mathrm{~nm}[7]$.

Basically, optical temperature sensors are used to measure physical parameters such as strain, temperature and sensor [8]. These can be achieved when these parameters modulate the propagation properties such as intensity, phase, wavelength, and polarization [9]. Recently, numerous FBG sensors have 
continuously been industrialized thus their functions have extended swiftly into the related areas as the measurement of gas traces, strain, angle of torsion, electric current, displacement, and torque [10]. FBG also allows many gratings to be printed in one strip of fiber, and at the same times, their addresses are structured using multi-channel technology [11]. From all the capabilities of FBG that has been explained, it approves that FBG can be a sensing system that are capable in a distributed detection, and a multi-channel distributed sensor system [12]. The applications of FBG have become extreme interest to researchers due to high electromagnetic that are generated by natural sources [13].

Different physical quantities such as motion, temperature, strain, bending and pressure has become an extension research of FBG sensors in the area of Optical Fiber Sensors [14]. The most common parameters in industries for monitoring different procedures are temperature. Several techniques can be used to raise the temperature sensitivity of FBG. For example, dissimilar kind of metal materials are used as driving element and to coat the FBG whose coefficient of thermal expansion is expected to be larger compared to silica [15]. Furthermore, a lot of methods for improving thermal sensitivity of FBGs have been introduced by the researchers such as packaging, coating, cascading and bimetallic strips [16-18].

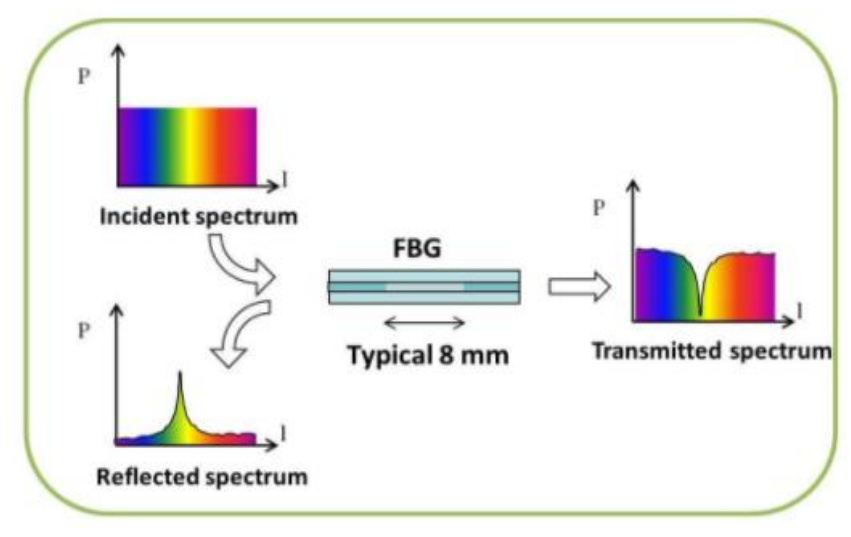

Figure 1. Working principle of FBG [3]

In this paper, different types of FBG such as Acrylate FBG, Bare FBG, Bimetallic Acrylate FBG, Bimetallic Bare FBG and Ceramic FBG were chose to determine the sensitivity for every type of FBG on the four different plates at different temperatures. The four different plates are Aluminium, Aluminium Coating, Zinc and Zinc Coating. Those plates have been used because of their excellent thermal conductivity at the range of temperature $23^{\circ} \mathrm{C}$ to $70^{\circ} \mathrm{C}$. Thermal conductivity defined as ability of a metal to conduct heat. The thermal conductivity of Aluminium, Zinc and Copper are $237 \mathrm{~W} / \mathrm{mK}, 116 \mathrm{~W} / \mathrm{mK}$ and $385 \mathrm{~W} / \mathrm{mK}$ respectively. Two metals which are Copper and Zinc have been chosen to design the Bimetallic Strips FBG due to the Coefficient Thermal Expansion (CTE). CTE is defined as fractional increase in length per unit rise in temperature. CTE for Copper $(\mathrm{Cu})$ and $\mathrm{Zinc}(\mathrm{Zn})$ are $16-16.7^{\circ} \mathrm{C}^{-1}$ and $30-35^{\circ} \mathrm{C}^{-1}$ respectively where they have larger CTE compared to silica.

The enhancement FBG temperature sensitivity sensor with dissimilar forms of materials which are covered on the FBGs with thermal expansion coefficient higher as compared to silica is presented in [19]. The first thing that need to consider in coating of FBG are the thermal expansion coefficient materials must higher than silica. So, the chosen of five materials to be covered on FBG with a thickness of $20 \mu \mathrm{m}$ are Lead, Indium, Aluminium, Copper and Polymethyl Methacrylate (PMMA). Based on result analysis, the total shift Bragg Wavelength shows PMMA FBG is found to be $23.5 \mathrm{~nm}$ and the basic FBG is $0.4 \mathrm{~nm}$ while copper, Aluminium, lead and indium are $6.4 \mathrm{~nm}, 8.9 \mathrm{~nm}, 10.8 \mathrm{~nm}$, and $12.7 \mathrm{~nm}$ respectively. Other than that, PMMA showed the highest sensitivity of $94.0 \mathrm{pm} / \mathrm{K}$ while the other materials of copper, Aluminium, lead and indium have $25.6 \mathrm{pm} / \mathrm{K}, 35.6 \mathrm{pm} / \mathrm{K}, 43.2 \mathrm{pm} / \mathrm{K}$ and $50.8 \mathrm{pm} / \mathrm{K}$ respectively. From the analysis, PMMA and Indium has improved the sensitivity of temperature while PMMA enhanced the highest percentage improvement and the best coating material. Unfortunately, this paper does not show the solutions guided to produce PMMA and no schematic experimental setup on the coating of FBG with different materials.

The next research that will be reviewed is the study of FBG temperature response with two dissimilar coating thicknesses and to determine the Bragg wavelength change between $77 \mathrm{~K}$ to $303 \mathrm{~K}$. Using the phase mask technique, two detached uniform FBG's were decorated in photosensitive fiber SM1500 for coating the FBG [20]. With the main purpose to get different coating thickness, a simple dip coating has been 
chosen where FBG's were immersed into two dissimilar concentration of PMMA solutions thus it will lift from two solutions at uniform speed which resulted $10.02 \mu \mathrm{m}$ and $20.97 \mu \mathrm{m}$ coated. Result analysis shows the PMMA coated FBG of $20.97 \mu \mathrm{m}$ thickness has temperature sensitivity 5.6 times better than bare FBG and the temperature response curve are nonlinear. Meanwhile, the total shift in Bragg Wavelength for bare FBG, $10.02 \mu \mathrm{m}$ and $20.97 \mu \mathrm{m}$ thickness coated are $1.62 \mathrm{~nm}, 3.95 \mathrm{~nm}$ and $8.97 \mathrm{~nm}$ respectively. Other than that, loss of Bragg wavelength reflection power for bare FBG, $10.02 \mu \mathrm{m}$ and $20.97 \mu \mathrm{m}$ thickness coated are $43.52 \mathrm{nW}$, $122.69 \mathrm{nW}$ and $146.87 \mathrm{nW}$, respectively. So, it has been concluded that the greater thickness of PMMA coated, having large coefficient of thermal expansion for the sensor operated from $70 \mathrm{~K}$ to $303 \mathrm{~K}$. Unfortunately, this paper does not show the solutions guided to produce PMMA. A research that used bimetallic strips method has been done by P. S. Reddy et al [21]. The objective of this research is to design high sensitivity FBG sensor. An FBG sensor design is proposed whereas the bare FBG is inserted between surfaces of ceramic block and bimetallic strip (Design 1) and another design is bare FBG glued between two bimetallic strips (Design 2). The analysis for this study presents the temperature response of the bare FBG, Design 1 and Design 2 are $\left(\boldsymbol{\delta} \lambda_{B} / \mathrm{dT}=11 \mathrm{pm} /{ }^{\circ} \mathrm{C}\right),\left(\boldsymbol{\delta} \lambda_{B} / \mathrm{dT}=32 \mathrm{pm} /{ }^{\circ} \mathrm{C}\right)$, and $\left(\boldsymbol{\delta} \lambda_{B} / \mathrm{dT}=64 \mathrm{pm} /{ }^{\circ} \mathrm{C}\right)$ respectively. The sensitivity also enhanced by 3 times and 6 times more than bare FBG for Design 1 and Design 2. The conclusion for this paper is the temperature sensitivity for the proposed FBG that can be highly improved and controlled together with good stability, linearity, and repeatability via the bimetallic strips.

This paper presents the design and characterization of metal plate temperature sensor based on Fiber Bragg Grating (FBG). Five types of FBGs were employed such as Acrylate FBG, Bare FBG, Bimetallic Acrylate FBG, Bimetallic Bare FBG and Ceramic FBG to determine the sensitivity on four different plates at $23^{\circ} \mathrm{C}$ to $70^{\circ} \mathrm{C}$, experimentally. The four different plates are attached to the FBGs for characterization. The four plates are Aluminium, Aluminium Coating, Zinc and Zinc Coating and they are used because of excellent thermal conductivity. Two metals which are Copper and Zinc have been chosen to design the Bimetallic Strips FBG due to the Coefficient Thermal Expansion (CTE) to improve their sensitivity.

\section{RESEARCH METHODOLOGY}

The Bragg wavelength, $\lambda_{B}$ of FBG is a function of the periodicity of grating, $\Lambda$ and the effective refractive index of fiber, $n_{e f f}$. The equation of Bragg reflection wavelength is given below [22]:

$$
\lambda_{\mathrm{B}}=2 \mathrm{n}_{\mathrm{eff}} \Lambda
$$

The temperature effect of Bragg wavelength with constant strain is conquered almost $95 \%$ by thermo-optic effect. The wavelength modification due to temperature change on FBG is shown below where $\alpha$ is the CTE of fiber material for example silica [23]:

$$
\frac{\delta \lambda_{\mathrm{B}}}{\lambda_{\mathrm{B}}}=\alpha+\frac{1}{\mathrm{n}} \frac{\mathrm{dn}}{\mathrm{dT}}
$$

FBG is attached to a bimetal thus when heated, the product of strain effect, $\Delta \varepsilon$ and temperature variation, $\Delta \mathrm{T}$ is equal to wavelength shift. The equation is shown below [24]:

$$
\frac{\Delta \lambda_{\mathrm{B}}}{\lambda_{\mathrm{B}}}=\mathrm{K}_{\varepsilon} \Delta \varepsilon+\mathrm{K}_{\mathrm{T}} \Delta \mathrm{T}
$$

where $K_{\varepsilon}$ are strain sensitivity and $K_{T}$ are temperature sensitivity of FBG. A bimetallic strip consists of two metals with dissimilar CTE. Therefore, there are two temperature variations, $\Delta T_{\text {bimetal }}$ and $\Delta T_{F B G}$ because of transfer loss between bimetallic sheet and FBG. They have different in values even though heat is produced from the similar source. The relationship between wavelength shift and temperature is linear. The FBG wavelength shift is bonded to bimetal rewritten as below [25]:

$$
\frac{\Delta \lambda_{\mathrm{B}}}{\lambda_{\mathrm{B}}}=\mathrm{K}_{\varepsilon} \Delta \alpha \Delta \mathrm{T}_{\text {bimetal }}+\mathrm{K}_{\mathrm{T}} \Delta \mathrm{T}_{\mathrm{FBG}}
$$

For the experimental setup, different types of FBG such as Acrylate FBG, Bare FBG, Bimetallic Acrylate FBG, Bimetallic Bare FBG and Ceramic FBG were used to determine the sensitivity for every type of FBG on four different plates at different temperatures. Two metals which are Copper and Zinc had been chosen to design the Bimetallic Strips FBG based on the Coefficient Thermal Expansion (CTE). The Bare 
FBG was bonded onto Zinc surface which has higher CTE than Copper. Then, it follows by Acrylate FBG also bonded onto Zinc surface to form Bimetallic Acrylate and Bare FBG.

The four different plates are Aluminium, Aluminium Coating, Zinc and Zinc Coating. Those plates were chosen because of their excellent thermal conductivity at the range of temperature between $23^{\circ} \mathrm{C}$ to $70^{\circ} \mathrm{C}$ which can vary by using hot plate. The metals were coated with DPI Anchor Spray Paint. Digital thermometer was used to monitor the medium and it has been used as reference for collecting the data observed on the desired temperature. 11 readings for each type of FBGs on the plates were taken with increment of $5^{\circ} \mathrm{C}$ for temperature from $23^{\circ} \mathrm{C}$ to $70^{\circ} \mathrm{C}$.

Firstly, Acrylate FBG was placed on the Zinc plate and hotplate. C-Band ASE Broadband Source and OSA were connected to each end of the FBG respectively. Next, the temperature of the hotplate was increased for $5^{\circ} \mathrm{C}$ gradually from $23^{\circ} \mathrm{C}$ to $70^{\circ} \mathrm{C}$ resulted in 11 readings of reflected wavelength from the OSA. The steps were repeated with 4 different FBGs on the 4 different plates at the same temperature range. The schematic of the setup is shown below in Figure. 2.

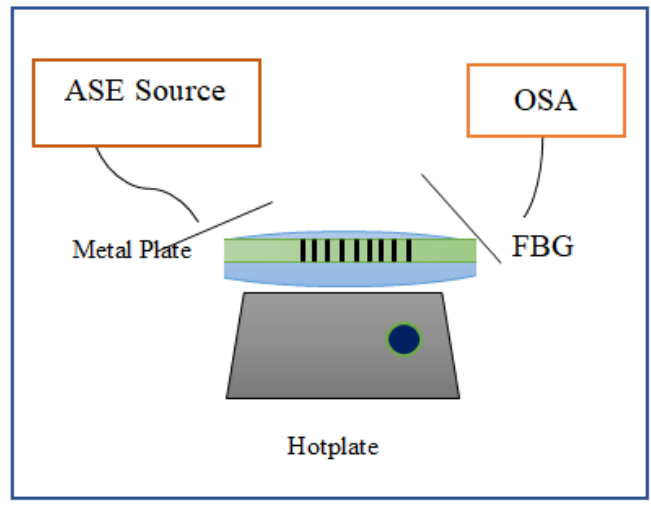

Figure 2. The schematic experimental setup

For the experiment, five types of FBGs on four different plates at temperature ranges between $23^{\circ} \mathrm{C}$ to $70^{\circ} \mathrm{C}$ have been conducted using Optical Spectrum Analyzer (OSA), and C-Band ASE Broadband Source. $\mathrm{C}$-Band ASE was functioning as a monitoring source. This source will be transmitted to FBG thus the transmission spectrum of FBG will be monitor by using OSA. Lastly, the data from the OSA was collected and analyzed. The experimental setup is shown in Figure 3.

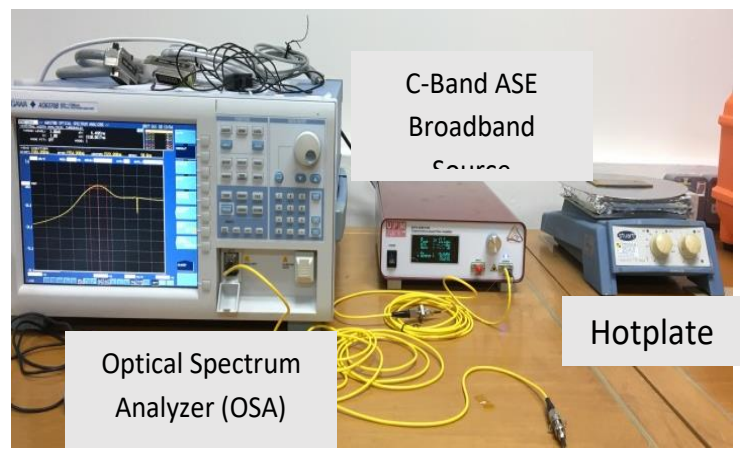

Figure 3. Experimental setup for temperature sensor

\section{RESULTS AND ANALYSIS}

Figure. 4 to 8 show temperature response of FBGs with four types of metal plates which results in the sensitivity of temperature sensor. Five FBGs are used such as Acrylate, Bare, Bimetallic Acrylate, Bimetallic Bare and Ceramic. The metal plates employed are Aluminium, Aluminium Coating, Zinc and Zinc Coating. Aluminium and Zinc Coating plates were painted with aerosol. 
It can be observed that there is linear relation between Bragg Wavelength Shift, $\Delta \lambda$ and temperature. As temperature increases, Bragg Wavelength Shift, $\Delta \lambda$ also increases. This is because of thermal expansion of gratings that cause changes of FBGs refractive index. Inconsistency of the wavelength shift for this FBG is due to thermal conductive of metal plates. Thus, it is found that Ceramic FBG has the highest sensitivity to measure temperature metal plate such as Aluminium, and Zinc with sensitivity of 50.4 and $59.7 \mathrm{pm}\left({ }^{\circ} \mathrm{C}\right)^{-1}$. This is due to the fast response and high stability of Ceramic FBG while Acrylate FBG suitable to measure temperature of Aluminium Coating plate and Bare FBG is the most suitable to measure the temperature of Zinc Coating plate with sensitivity of 34.9 and $17.8 \mathrm{pm}\left({ }^{\circ} \mathrm{C}\right)^{-1}$ respectively.

Figure 6 and 7 show the result for Bimetallic FBG. Two metals which are Copper and Zinc have been chosen to design the Bimetallic Strips FBG due to the Coefficient Thermal Expansion (CTE). It is designed to increase the sensitivity of the temperature sensor. It can be perceived that Bimetallic bare FBG has higher sensitivity as compared to Bare FBG in determining the temperature of metal plates without coating. This is due to excellent thermal expansion of Bimetallic itself when in contact with metal plates. Meanwhile, both Bimetallic FBGs also have higher sensitivity as compared to Ceramic FBG when in contact with Aluminium Coating and Zinc Coating. This is because of some heat trapped in the layer of coating plates which will maintain the conduciveness between the metal coating plates and Bimetallic FBGs. It can also be observed that this technique is able to measure different temperature of various metal plates with and without coating.

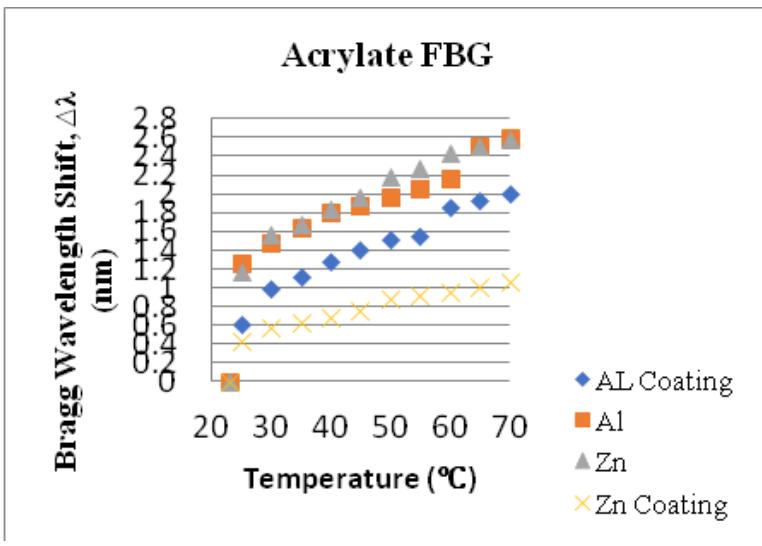

Figure 4. Bragg wavelength shift of Acrylate FBG versus temperature response for various metal plates

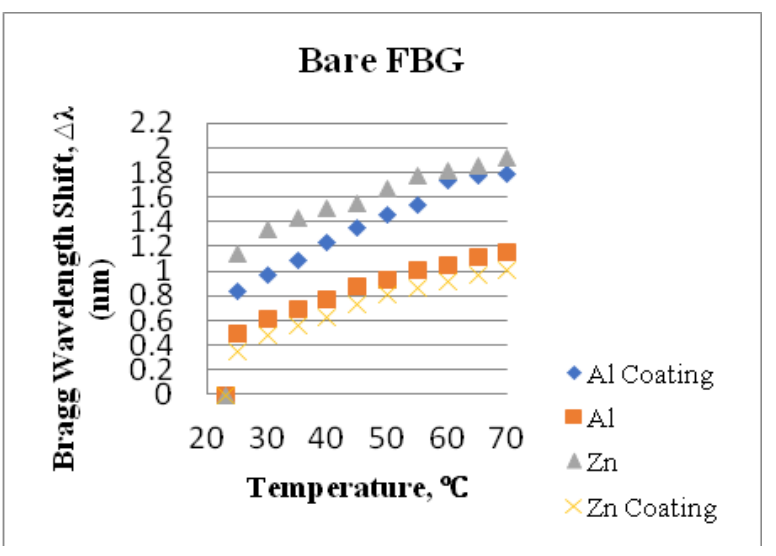

Figure 5. Bragg wavelength shift of Bare FBG versus temperature response for various metal plates

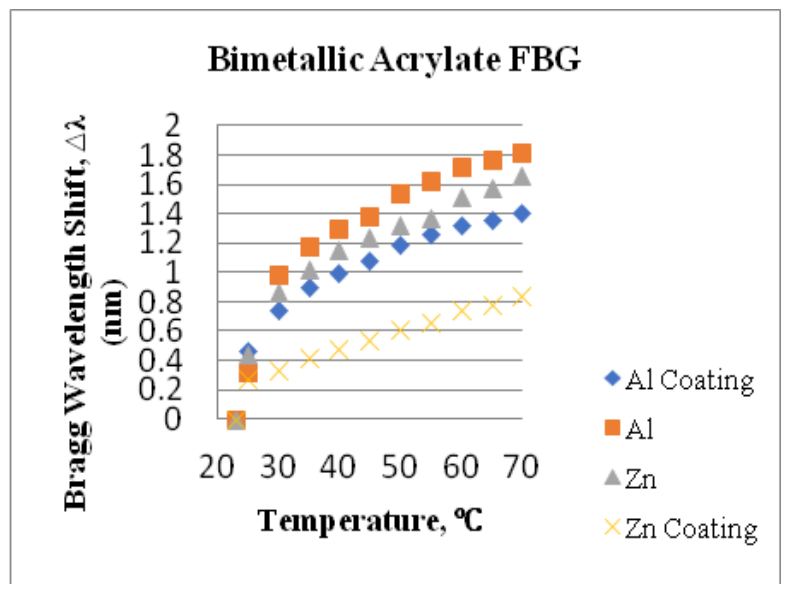

Figure 6. Bragg wavelength shift of bimetallic acrylate FBG versus temperature response for various metal plates

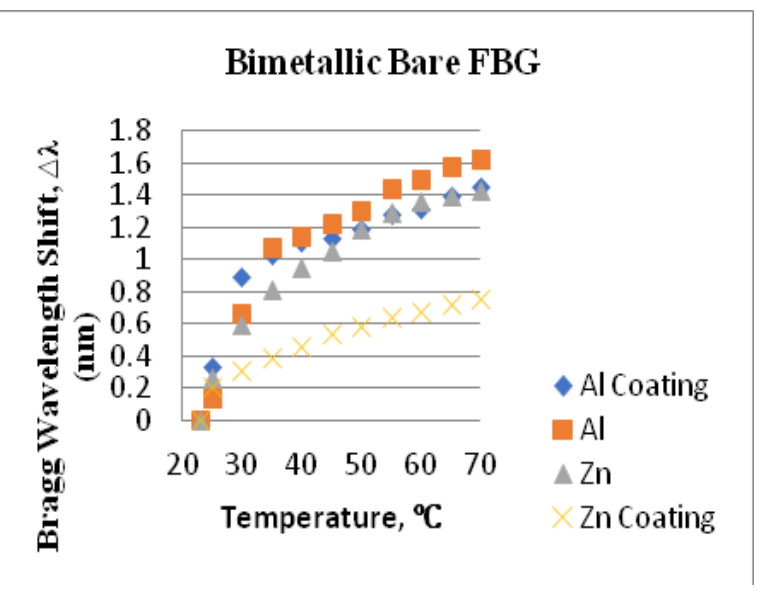

Figure 7. Bragg wavelength shift of bimetallic bare FBG versus temperature response for various metal plates 


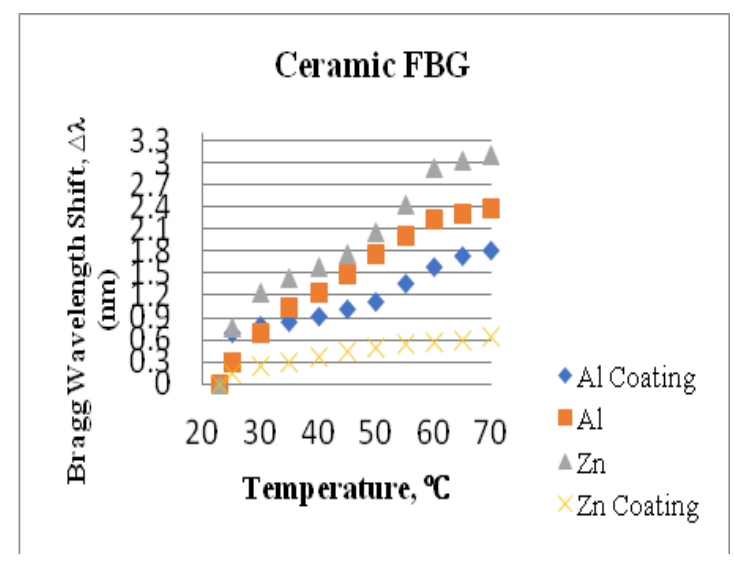

Figure. 8. Bragg wavelength shift of ceramic FBG versus temperature response for various metal plates

Table 1 shows the sensitivity for five types of FBGs which are Acrylate FBG, Bare FBG, Bimetallic Acrylate FBG, Bimetallic Bare FBG and Ceramic FBG with Aluminium, Aluminium Coating, Zinc and Zinc Coating plates at temperature ranges $20-70^{\circ} \mathrm{C}$.

Table 1. Sensitivity of FBGs with Various Metal Plates at $20 \mathrm{oC}$ to $70 \mathrm{oC}$

\begin{tabular}{lcccc}
\hline Type of Plate FBG & \multicolumn{4}{c}{ FBG Sensitivity $\mathrm{pm}\left({ }^{\circ} \mathrm{C}\right)^{-\mathbf{1}}$} \\
& Aluminium & Aluminium Coating & Zinc & Zinc Coating \\
\hline Acrylate & 38.3 & 34.9 & 40.7 & 17.3 \\
Bare & 19.0 & 29.5 & 26.6 & 17.8 \\
Bimetallic Acrylate & 33.5 & 24.2 & 28.8 & 14.8 \\
Bimetallic Bare & 31.9 & 24.4 & 28.0 & 14.0 \\
Ceramic & 50.40 & 22.80 & 59.70 & 12.40 \\
\hline
\end{tabular}

From Table 1, Ceramic FBG shows the highest sensitivity that in contact with Aluminium plate which is $50.40 \mathrm{pm}\left({ }^{\circ} \mathrm{C}\right)^{-1}$ followed by Acrylate $\mathrm{FBG}$ with $38.3 \mathrm{pm}\left({ }^{\circ} \mathrm{C}\right)^{-1}$, Bimetallic Acrylate $\mathrm{FBG}$, Bimetallic Bare FBG, and Bare FBG with sensitivity 33.5, 31.9 and $19.00 \mathrm{pm}\left({ }^{\circ} \mathrm{C}\right)^{-1}$ respectively.

Aluminium coating plate is an Aluminium plate painted with aerosol paint. It is found that this will result in different sensitivity as compared to Aluminium plate. For Aluminium Coating plates, Acrylate FBG shows the highest sensitivity with $34.9 \mathrm{pm}\left({ }^{\circ} \mathrm{C}\right)^{-1}$. This is followed by Bare, Bimetallic Bare, Bimetallic Acrylate, and Ceramic FBG is $29.5,24.4,24.2$ and $22.8 \mathrm{pm}\left({ }^{\circ} \mathrm{C}\right)^{-1}$ respectively.

Ceramic FBG that in contact with Zinc plate has the highest sensitivity which is $59.70 \mathrm{pm}\left({ }^{\circ} \mathrm{C}\right)^{-1}$ as compared to other FBGs. Then, it is followed by Acrylate, Bimetallic Acrylate, Bimetallic Bare and Bare FBG with sensitivity for each are 40.7, 28.8, 28.0, $26.6 \mathrm{pm}\left({ }^{\circ} \mathrm{C}\right)^{-1}$ respectively.

Zinc coating plate is a Zinc plate painted with aerosol paint. It is found that this will result in different sensitivity as compared to Zinc plate. For Zinc Coating plate, the highest sensitivity is by using Bare FBG with $17.8 \mathrm{pm}\left({ }^{\circ} \mathrm{C}\right)^{-1}$. Then it follows by Acrylate, Bimetallic Acrylate, Bimetallic Bare, and Ceramic FBG with sensitivity $17.3,14.8,14.0$ and $12.4 \mathrm{pm}\left({ }^{\circ} \mathrm{C}\right)^{-1}$ respectively.

Based on Table 1, most of the FBGs have the best contact with Aluminium plate and Zinc plate because it has high thermal conductive which is $237 \mathrm{~W} / \mathrm{mK}$ and $116 \mathrm{~W} / \mathrm{mK}$ respectively. Since metal plates have high thermal conductivity, Bragg Wavelength of FBG shifted when temperature produces thermal expansion of fiber and changes the refractive index of fiber core efficiently. Other than that, it can be observed that most of FBGs except Bare FBG have the best contact with uncoated metal plates which is Aluminium and Zinc plates. This is due to heat resistance of the coatings that cause the minor temperature drop of metal coating plates thus it will affect the wavelength shift of fiber.

In addition, by comparing all types of FBG with metal plates, Ceramic FBG is the most sensitive FBG when in contact with two metal plates such as Aluminium and Zinc because this FBG has dominate two out of four metal plates with sensitivity of $50.40 \mathrm{pm}\left({ }^{\circ} \mathrm{C}\right)^{-1}$ and $59.70 \mathrm{pm}\left({ }^{\circ} \mathrm{C}\right)^{-1}$, respectively. This happens due to Ceramic Coated FBG has high thermal expansion, fast response and has high stability compare to the other four FBGs thus leads to high sensitivity of FBG with temperature. Meanwhile, Acrylate FBG has the highest sensitivity with Aluminium Coating plate which is $34.90 \mathrm{pm}\left({ }^{\circ} \mathrm{C}\right)^{-1}$ and Bare $\mathrm{FBG}$ has the highest sensitivity which is $17.8 \mathrm{pm}\left({ }^{\circ} \mathrm{C}\right)^{-1}$ when in contact with Zinc Coating plate. 


\section{CONCLUSION}

In conclusion, there is linearity relationship between Bragg Wavelength Shift, $\Delta \lambda$ and temperature. As temperature increases, Bragg Wavelength Shift, $\Delta \lambda$ also increases. It is found that Ceramic FBG is the most sensitive FBG with sensitivity of $59.70 \mathrm{pm}\left({ }^{\circ} \mathrm{C}\right)^{-1}$ when in contact with Zinc metal plates. This is because it has high thermal expansion of gratings which results in changes of FBGs refractive index. Different wavelength shift for this FBG is also due to thermal conductive of metal plates. Most of the FBGs such as Acrylate FBG, Bimetallic Acrylate FBG, Bimetallic Bare FBG and Ceramic FBG are compatible with Aluminium and Zinc metal plates compared to Aluminium Coating and Zinc Coating metal plates because it has high thermal conductive which is $237 \mathrm{~W} / \mathrm{mK} 116 \mathrm{~W} / \mathrm{mK}$. Besides, it can be observed that all the types of FBG have the best contact with uncoated metal plates due to the heat resistance of metal coating plates.

\section{ACKNOWLEDGEMENTS}

The author wishes to thank Universiti Teknologi MARA (UiTM) under Bestari research grant 600-IRMI/PERDANA 5/3 BESTARI (082/2018) for supporting this project.

\section{REFERENCES}

[1] Chuan Li, Yi-Mo Zhang, Tie-Gen Liu, et al. "Distributed Optical Fiber Bi-directional Strain Sensor for Gas Trunk Pipelines". Optics and Lasers in Engineering, (2001), 36: 41-47.

[2] Kenneth O. Hill, Gerald Meltz, "Fiber Bragg Grating Technology Fundamentals and Overview", Journal of lightwave technology, vol. 15.8, pp. 1263-1276, 1997.

[3] Hill, K.O.; Fujii, Y.; Johnson, D. C.; Kawasaki, B. S., "Photosensitivity in Optical Fiber Waveguides: Application to Reflection Fiber Fabrication", Appl. Phys. Lett. 32 (10): 647, 1978.

[4] S. Otani, H. Hiraishi, M. Midorikawa, et al. "Development of Smart Systems for Building Structures". SPIE, (2000), 3988: 2-9

[5] K. A. Fidanboylu, H. S. Efendioglu, "Fiber Optic Sensors and Their Applications", 5th International Advanced Technologies Symposium (IATS'09), vol. 6, no. 2009.

[6] S. Anania, A. Unnikrishnan, A. Aparna, G. R. Parvathi, S. D. Baby Sreeja and P. Mohan, "Analytical Study of FBG Spectrum for Temperature Sensing Applications," 2018 Second International Conference on Inventive Communication and Computational Technologies (ICICCT), Coimbatore, 2018, pp. 1109-1113.

[7] T.Mizunami, H.Tatehata and H.Kawashima, "High-Sensitivity Cryogenic Fiber Bragg Grating Temperature Sensors using Teflon Substrates", Meas Sci Technol 12, 914-917(2001)

[8] Zhang, A. Ping et al., "Advances in Optical Fiber Bragg Grating Sensor Technologies", Photonic Sensors, vol. 2.1, pp. 1-13, 2012.

[9] Xu Yanping et al., "Multi-Parameter Fiber-Optic Sensors based on Fiber Random Grating", Optical Fiber Sensors Conference (OFS) 2017 25th. IEEE, 2017.

[10] Inoue Akira, "Fabrication and Application of Fiber Bragg Grating-A Review", Optoelectron. Dev. Technol., vol. 10.1, pp. 119-130, 1995.

[11] Yong Zhao. "Sensing Principle and Utility Technique of Fiber Grating Sensors". Beijing, Tsinghua University Press, 2007.

[12] L. Xue, J. Liu, Y. Liu, L. Jin, S. Gao, B. Dong, Q. Zhao, and X. Dong, "Method for Enhancing Temperature Sensitivity of Fiber Bragg Gratings based on Bimetallic Sheets", Appl. Opt., vol. 45, no. 31, pp. 8132-8135, Nov. 2006.

[13] C.-S. Park, K.-Il Joo, S.-W, Kang, H.-R. Kim, "A PDMS-Coated Optical Fiber Bragg Grating Sensor for Enhancing Temperature Sensitivity”, J. Optik Soc. Korea 15 (4) (2011) 329-334.

[14] P.sunita, V.Ugale, Mishra, "Formation and Characterization of Non-Uniform Long and Ultra Long, Period Reversible Optical Fiber Grating”, Optik-Int. J. Light Optic 125 (15) (2014) 3822-3824.

[15] S. Sandlin, T. Kinnunen, J. Rämö, S. Mika, "A Simple Method for Metal Re-Coating of Optical Fiber Bragg Gratings", Surf. Coat. Technol. 201 (2006) 3061-3065.

[16] G.-C. Lin, L. Wang, C. C. Yang, M. C. Shih, and T. J. Chung, "Thermal Performance of Metal-Clad Fiber Bragg Grating Sensors", IEEE Photon. Technol. Lett., vol. 10, no. 3, pp. 406-408, Mar. 1998.

[17] J.Jung, H.Nam, B.Lee, J.O.Byun and N.S.Kim, "Fiber Bragg Grating Temperature Sensor with Controllable Sensitivity", Appl. Opt., vol. 38, no. 13, pp. 2572-2754, May 1999.

[18] C.Lupi, F.Felli, A.Brotzu, M.A.Caponero, and A.Paolozzi, "Improving FBG Sensor Sensitivity at Cryogenic Temperature by Metal Coating”,IEEE Sens. J., vol. 8, no. 7, pp. 1299-1304, Jul. 2008.

[19] Vivekanand Mishra, Mukesh Lohar, Angela Amphawan, "Improvement in Temperature Sensitivity of FBG by Coating of Different Materials", Optik - International Journal for Light and Electron Optics, Volume 127, Issue 2, January 2016, Pages 825-828.

[20] D. Sengupt, M. Sai Shankar, P. Saidi Reddy, R. L. N. Sai Prasad, K. S. Narayana and P. Kishore, "An Improved Low Temperature Sensing using PMMA Coated FBG," 2011 Asia Communications and Photonics Conference and Exhibition (ACP), Shanghai, 2011, pp. 1-5. 
[21] P. S. Reddy et al., "Method for Enhancing and Controlling Temperature Sensitivity of Fiber Bragg Grating Sensor Based on Two Bimetallic Strips," in IEEE Photonics Journal, vol. 4, no. 3, pp. 1035-1041, June 2012.

[22] D. Sengupt, M. Sai Shankar, P. Saidi Reddy, R. L. N. Sai Prasad, K. S. Narayana and P. Kishore, in: Proceedings of the Spie-Osa-IEEE Asia Communications And Photonics. "An Improved Low Temperature Sensing using PMMA Coated FBG”, 8311 (2011) 831103.

[23] Hill, K.O.; Meltz, G. "Fiber Bragg Grating Technology Fundamentals and Overview". J. Lightwave Technol. 1997, 15, pp. 1263-1276.

[24] Rao, Y.-J. "In-Fibre Bragg Grating Sensors". Meas. Sci. Technol. 1997, 8, 355.

[25] Clyne, T.W.; Gill, S.C. "Residual Stresses in Thermal Spray Coatings and Their Effect on Interfacial Adhesion: A Review of Recent Work". J. Therm. Spray Technol. 1996, 5, pp. 401-418.

\section{BIOGRAPHIES OF AUTHORS}
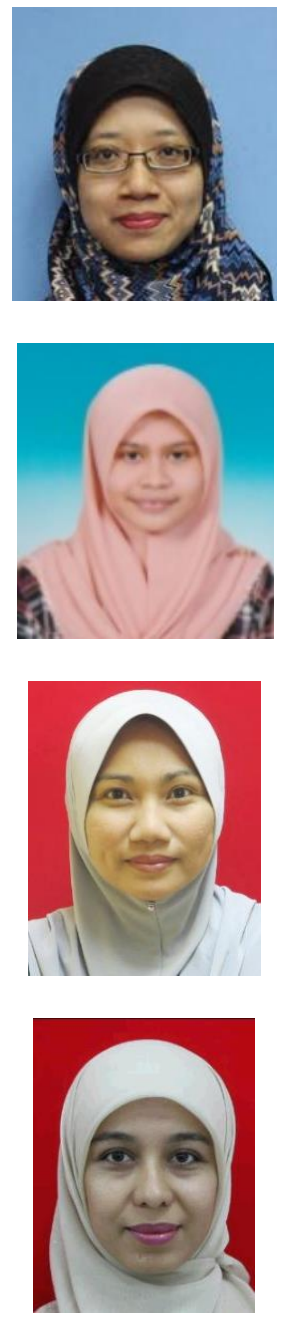

Nani Fadzlina Naim received the B.Eng. degree in Electrical and Electronics Engineering and M.Eng degree in Electronics and Communication Engineering from Universiti Teknologi Malaysia (UTM) in 2005 and 2007, respectively. She received her PhD in 2015 in Electrical, Electronics and Systems Engineering from Universiti Kebangsaan Malaysia (UKM). She is currently a senior lecturer at Faculty of Electrical Engineering, Universiti Teknologi MARA (UiTM). Her current research interests are in the area of optical networks design, optical network monitoring, Fiber Bragg Grating, optical sensing technology and its application.

Nur Shahira Binti Anuar received her Bachelor of Electronic Engineering from Universiti Teknologi MARA UiTM in 2016. Then, she received her MSc. in Telecommunication and Information Engineering in 2018. Currently, she is a broadcast engineer at Radio, Televisyen Malaysia (RTM) Sibu, Sarawak. Her research interests are in optical sensor and Fiber Bragg Grating.

Suzi Seroja Sarnin received her Bachelor of Electrical and Electronics (B. Eng) in Communication field in 1999 from Universiti Teknologi Malaysia (UTM), Skudai, Johor. She completed her Master of Microelectronics (MSc.) from Universiti Kebangsaan Malaysia in 2005. She received her $\mathrm{PhD}$ in Electrical engineering in 2018. Currently, she is a senior lecturer at Faculty of Electrical Engineering, Universiti Teknologi MARA (UiTM). Her research interests are in wireless communication and Internet of Thing (IoT).

Norsuzila Ya'acob is Associate Professor at the Department of Communication Engineering, Faculty of Electrical Engineering, Universiti Teknologi MARA (UiTM). In 2010, she was awarded a PhD degree in Electrical, Electronic \& Systems Engineering from Universiti Kebangsaan Malaysia (UKM), Malaysia. She received her MSc degree from University Putra Malaysia (UPM) in 2000. She also obtained her B.Eng degree from University of Putra Malaysia (UPM), Malaysia in Electronics \& Computer Engineering in 1999. She is the Deputy Director for UiTM Satellite Centre at the FKE. Her research interests include Satellite, Space Weather, Remote Sensing, Mobile Communication and Signal Processing. 